\title{
REVIEW
}

\section{Cell and molecular biology of Notch}

\author{
Ulla-Maj Fiúza and Alfonso Martinez Arias
}

Department of Genetics, University of Cambridge, Cambridge CB2 3EH, UK

(Correspondence should be addressed to U-M Fiúza; Email: umf20@cam.ac.uk)

\begin{abstract}
Notch signalling is a cell-cell communication process, which allows the establishment of patterns of gene expression and differentiation, regulates binary cell fate choice and the maintenance of stem cell populations. So far, the data published has elucidated the main players in the Notch signalling pathway. However, its regulatory mechanisms are exhibiting an increasing
\end{abstract}

complexity which could account for the multitude of roles it has during development and in adult organisms. In this review, we will describe the multiple roles of Notch and how various factors can regulate Notch signalling.

Journal of Endocrinology (2007) 194, 459-474

\section{The structure of Notch and the Notch signalling pathway}

The Notch genes encode members of a family of receptors that mediate short-range signalling events. A prototypical Notch gene encodes a single transmembrane receptor composed in its extracellular region of a conserved array of up to 36 epidermal growth factor (EGF)-like repeats, involved in ligand interaction, and three juxtamembrane repeats known as Lin-12-Notch (LN) repeats which modulate interactions between the extracellular and the membrane-tethered intracellular domains (Wharton et al. 1985, Yochem et al. 1988). The intracellular region of Notch includes seven ankyrin repeats flanked by nuclear localization signals, a proline, glutamine, serine, threonine-rich (PEST) domain and a transactivation domain (TAD; reviewed in Fleming 1998, Lubman et al. 2004; see Fig. 1).

The first mutant in Notch was isolated by Dexter in Drosophila (1914), who described the lethality and the haploinsufficient wing notching that lends the name to the gene. New alleles were identified by Morgan and Bridges and the collection allowed the studies of Poulson on the recessive neurogenic phenotype (Metz \& Bridges 1917, Poulson 1939). Over the years, the analysis of these phenotypes eventually led to the discovery of different functions of Notch. Most importantly, in the last few years, it has uncovered three different Notch activities in development: lateral inhibition, boundary formation and cell fate assignation (Bray 1998). The first insights into the function and mode of action of Notch signalling came from studies in Drosophila melanogaster and Caenorhabditis elegans (Greenwald 1985, Wharton et al. 1985, Yochem et al. 1988, Fehon et al. 1990) which allowed the discovery of a core set of molecules involved in Notch signalling and lead to the understanding of how they organize into a signalling pathway.

In mammals, there are four Notch genes and five genes encoding ligands, three Delta-like and two Jagged (Fig. 1). In Drosophila, there is only one Notch-encoding gene, one Delta and one Jagged homologue (Serrate; Maine et al. 1995, Lissemore \& Starmer 1999). In C. elegans, there are two genes encoding for Notch (lin-12 and $g l p-1)$ and several Delta/ Serrate/Lag-2 (DSL) homologues (protein family of Notch ligands from DSL; Greenwald 1994, Maine et al. 1995, Lissemore \& Starmer 1999). The exploitation of the genetics of simpler organisms such as C. elegans and Drosophila has provided enormous insights into the mechanics of Notch signalling and has paved the way for better understanding how Notch acts in higher eukaryotes.

\section{The canonical pathway}

Notch is a single transmembrane protein, some of which is present at the cell surface. The ligands for Notch are also transmembrane proteins (Lissemore \& Starmer 1999) and, therefore, cell-cell contact is an important prerequisite to trigger the signalling event. A most important feature of Notch is that it acts, at the same times as a transmembrane receptor and as a transcription factor. At the cell surface, Notch is present as a heterodimer consisting of the EGF-like repeats and LN repeats linked non-covalently by a heterodimerization region to the rest of the molecule (Gordon et al. 2007; see Fig. 1). The C-terminal heterodimerization domain of extracellular Notch is a hydrophobic region that is able to form a stable complex with the 


\section{Extracellular region}

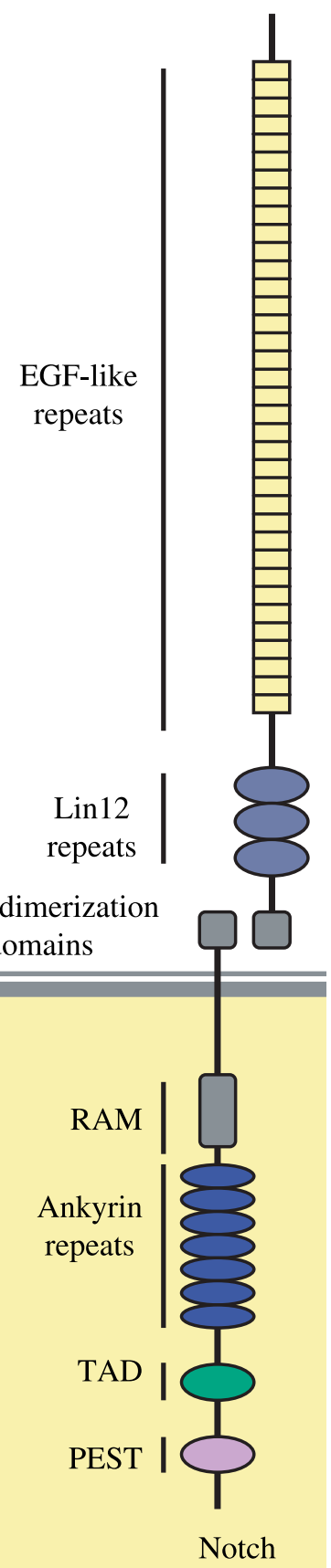

Figure 1 Structure of Notch and its ligands. Notch ligands, Delta and Jagged/Serrate, are composed of a DSL region responsible for the interaction with the Notch receptor and several EGF repeats. Jagged/Serrate also contains an extracellular cystein-rich region. Notch is composed by up to 36 EGF-like repeats. EGF repeats 11 and 12 are sufficient to mediate the interaction between Notch and its ligands. Notch also contains a cysteinerich region known as Lin-12 repeats in close proximity with heterodimerization domains that bind noncovalently extracellular Notch with membrane-tethered intracellular Notch. In its intracellular part, Notch has a region called RAM (RBPjk Associate Molecule) followed by repeated structural motifs named Ankyrin repeats (mediate the interaction between Notch and CBF1/Su(H)), a transactivation domain (TAD) and a PEST domain. The PEST domain is involved in the degradation of Notch. PM, plasma membrane. 
extracellular region of transmembrane Notch (Sanchez-Irizarry et al. 2004). The cleavage site of this structure, the S1 site (see Fig. 2), is processed by a furin-like convertase in the trans-Golgi, during the secretion process (Logeat et al. 1998, Nichols et al. 2007). This cleavage and the resulting structure appear to be essential for Notch activity in mammals (Logeat et al. 1998). In Drosophila, however, Notch seems to appear predominantly as a molecule not cleaved by furin and still retain its biological activity (Kidd \& Lieber 2002), although a number of studies would suggest that the heterodimer might also be the active form even though it is present at lower amounts (Rand et al. 2000). At the cell surface, Notch can interact with one of its ligands Delta (Dl) or Serrate (Ser) expressed in a neighbouring cell (Fehon et al. 1990). This interaction results in the shedding of the ectodomain and exposure of an extracellular metalloprotease site (S2 site) which thus becomes susceptible to cleavage by transmembrane proteases of the ADAM/TACE (a desintegrin and metallopeptidase/tumour necrosis factor $\alpha$ converting enzyme) family (Mumm et al. 2000, Nichols et al. 2007; see Table 1). As a result of this processing, the remaining membrane-tethered Notch fragment undergoes the S2 cleavage and two further intramembranous cleavages, named S3/S4, by $\gamma$-secretase activity of a membrane protein complex containing presenilin as the catalytic component (Kopan et al. 1996, Schroeter et al. 1998, Struhl \& Adachi 1998, Wolfe 2006). The intracellular domain of Notch is thus finally released and translocates into the nucleus where it regulates gene expression by acting as a co-activator of the transcription factor suppressor of hairless $(\mathrm{Su}(\mathrm{H})$; Fortini \& Artavanis-Tsakonas 1994, Struhl \& Adachi 1998).

Even though the biochemical details of the activation of Notch signalling are well established, the mechanisms that regulate this event are poorly understood. For example, where does the presenilin cleavage take place? How does Notch get to the nucleus? What is the role of trafficking in Notch signalling regulation? Understanding the underlying regulatory mechanisms is an important area of research due to the multiple roles of Notch in development. Recent

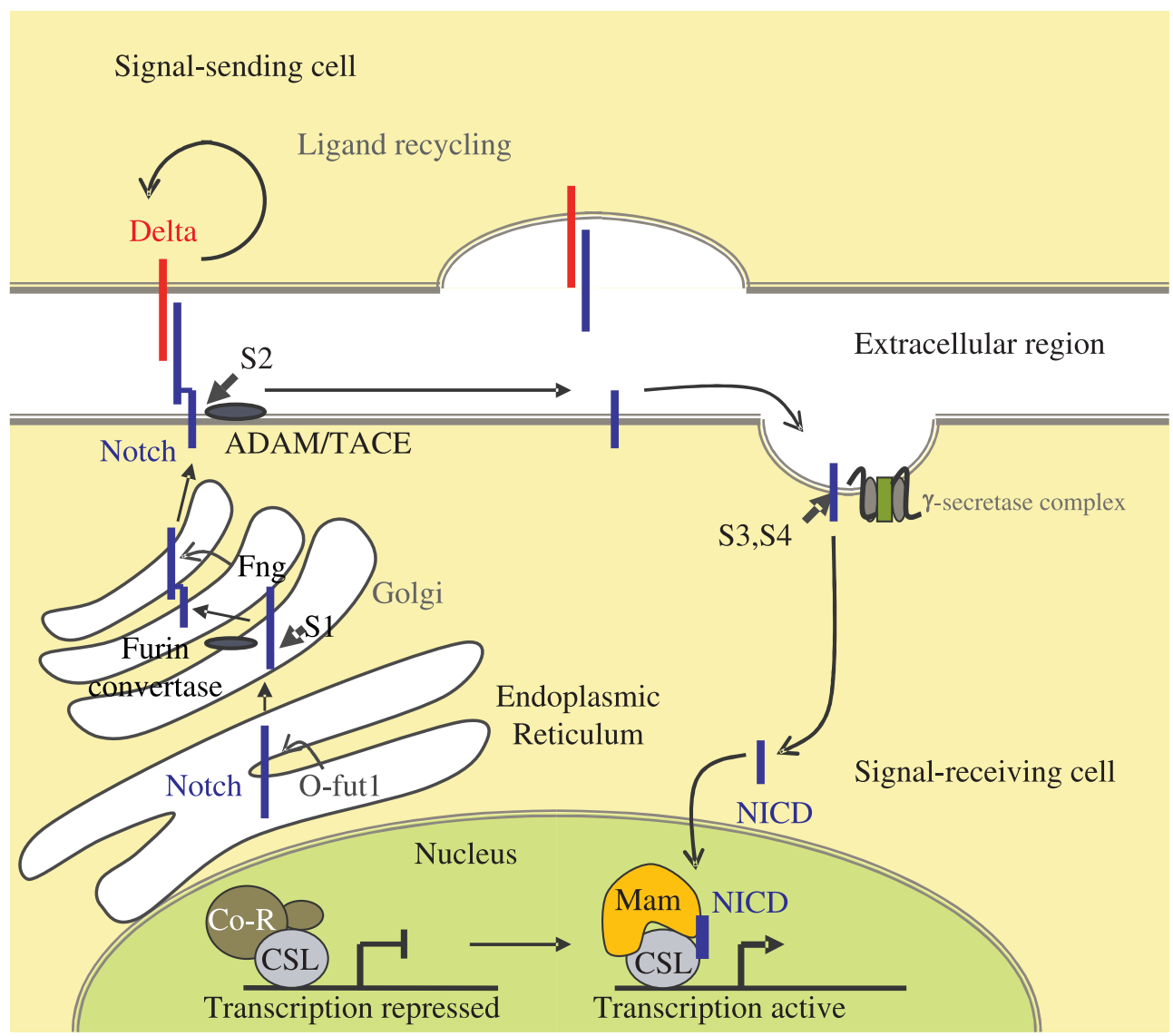

Figure 2 Canonical Notch signalling pathway. Notch binding to ligand elicits several steps of cleavage. The first one at the S2 site is mediated by the proteases ADAM 10 or by TACE (TNF- $\alpha$-converting enzyme). This catalyzes the processing of Notch in the intramembranous S2 and S3 sites by the $\gamma$-secretase complex. Thus, Notch intracellular domain (NICD) is released and translocates into the nucleus where it dislodges repressors (co-R) associated with the DNA-binding CSL transcription factor. NICD and CSL form a ternary complex together with Mastermind (Mam) that recruits transcription factors activating target gene expression. 
Table 1 Functional role of proteins involved in Notch signalling

\begin{tabular}{|c|c|c|c|}
\hline Mammals & Drosophila & C. elegans & Function \\
\hline CBF1/RBPJK & $\mathrm{Su}(\mathrm{H})$ & Lag-1 & DNA-binding transcription factor \\
\hline Mastermind $1-3$ & Mastermind & Lag-3 & Transcriptional co-activator \\
\hline POFUT-1 & OFUT-1 & OFUT-1 & $\begin{array}{l}\text { GDP-fucose protein } O \text {-fucosyltransferase that } \\
\text { modifies both the Notch receptor and its } \\
\text { ligands }\end{array}$ \\
\hline $\begin{array}{l}\text { Lunatic, manic and radical } \\
\text { Fringe }\end{array}$ & Fringe & No homologue identified & $\begin{array}{l}O \text {-fucosylpeptide } \beta-1,3-N \text {-acetylglucosami- } \\
\text { nyltransferase, modifies both Notch and its } \\
\text { ligands }\end{array}$ \\
\hline ADAM10, ADAM17 & $\begin{array}{l}\text { Kuzbanian, Kuzbanian- } \\
\text { like, TACE }\end{array}$ & SUP-17, ADM-4 & $\begin{array}{l}\text { Metalloproteases targeting S2 Notch cleavage } \\
\text { site }\end{array}$ \\
\hline $\begin{array}{l}\text { Presenilin 1-2, nicastrin, APH1, } \\
\text { PEN2 }\end{array}$ & $\begin{array}{l}\text { Presenilin, nicastrin, APH1, } \\
\text { PEN2 }\end{array}$ & $\begin{array}{l}\text { SEL-12, APH-1, APH-2, } \\
\text { PEN2 }\end{array}$ & $\begin{array}{l}\text { Proteins of the } \gamma \text {-secretase complex, which } \\
\text { targets Notch S3 and S4 cleavage sites }\end{array}$ \\
\hline Deltex $1-4$ & Deltex & No homologue identified & $\begin{array}{l}\text { Ring finger-type ubiquitin ligase, promotes } \\
\text { Notch localization towards Rab11-positive } \\
\text { vesicles }\end{array}$ \\
\hline Fbw7/Sel10 & Archipelago $^{a}$ & SEL-10 & $\begin{array}{l}\text { F-box protein that ubiquitinates phosphory- } \\
\text { lated sites of NICD eliciting its degradation }\end{array}$ \\
\hline $\begin{array}{l}\text { Mind bomb, skeletrophin, } \\
\text { neuralized } 1-2\end{array}$ & Mind bomb 1-2, neuralized & Y47D3A.22 & $\begin{array}{l}\text { E3 ubiquitin-protein ligases that targets Delta } \\
\text { and Jagged/Serrate and regulate their endo- } \\
\text { cytosis }\end{array}$ \\
\hline
\end{tabular}

${ }^{a}$ Not studied.

observations show that Notch regulatory processes encompass dissimilar mechanisms, such as chemical modifications, vesicular trafficking and interactions with other proteins (Haines \& Irvine 2003, Le Borgne 2006, Hu et al. 2006, Jaekel \& Klein 2006). These studies have begun to paint a more elaborate picture and elucidate some of these regulatory pathways, as we shall describe in the next section.

\section{Notch, ligands and interactions}

Interaction of Notch with its ligands results in the release of the intracellular domain. There is little known about the biochemical details of all the possible Notch-ligand interactions but it is clear that relative concentration is an important element and that this might determine whether the interaction is in cis or in trans (intracellular or intercellular; Klein et al. 1997, Micchelli et al. 1997, Klein \& Arias 1998, Sakamoto et al. 2002, Glittenberg et al. 2006). In addition, chemical modifications seem to be important for regulating these interactions (Sakamoto et al. 2002).

\section{Activating interactions with ligands}

Notch ligands, Delta and Jagged/Serrate, belong to the DSL family of proteins. In Drosophila, there is only one Delta and one Serrate. In mammals, the situation is more complex. For instance, humans and mice possess three Delta-like proteins, Delta1, 3 and 4 and two homologues for Serrate, known as Jagged1 and 2. The main structural difference between the Delta and Jagged/Serrate ligands is that the Jagged/Serrate contain in the extracellular region a greater number of EGF repeats and also insertions within the EGF repeats. Closer to the membrane, the Jagged/Serrate molecules contain a cysteine-rich region that is entirely absent from the Delta ligands (Lissemore \& Starmer 1999). The ligand region of most interest for Notch signalling is an extracellular cysteinerich region called DSL present in Delta and Jagged homologues. DSL mediates the interaction with Notch EGF-like repeats 11 and 12 (Rebay et al. 1991, Fleming 1998), although EGF repeats 23-25, where Abruptex alleles map, have also been shown to contribute towards the interaction between Notch and Delta but not for Serrate (Brennan et al. 1999a). The structure of the region encompassing EGF-like repeats 11-13 of human Notch 1 has been determined but the structure of the Notch-ligand complex remains unsolved (Hambleton et al. 2004). The interaction with the ligand is believed to lead to a conformational change that exposes the S2 site of cleavage causing Notch signalling activation (Gordon et al. 2007), but the details of the process remain to be investigated. 


\section{Modifications of Notch}

Notch and its ligands are glycoproteins and glycosylation of Notch has been shown to have a regulatory role on the ligand-binding properties of the receptors (Sakamoto et al. 2002). Studies in Drosophila have shown two glycosyltransferases that act on Notch: OFUT1 and Fringe. Drosophila Notch contains in the EGF-like repeats 23 consensus O-fucose sites targeted by OFUT1, a GDP-fucose protein O-fucosyltransferase that adds fucose to serine or threonine residues. The Ofut 1 loss of function phenotype in Drosophila is analogous to the Notch loss of function phenotype (Okajima \& Irvine 2002, Xu et al. 2005). OFUT1 could be essential for making Drosophila Notch (dmNotch) a functional receptor due to the $O$-fucosyl modifications but its chaperone activity could also be crucial for dmNotch acquiring its active conformation (Okajima \& Irvine 2002, Okajima et al. 2005). The O-fucosylated sites can be further modified by Fringe, a $\beta-1,3-N$-acetylglucosaminyltransferase. In Drosophila, Fringe modifications affect the ligand-binding properties of Notch by increasing the interaction affinity between Notch and Delta and inhibiting the interaction between Notch and Serrate (Panin et al. 1997, Bruckner et al. 2000, Lei et al. 2003). Notch ligand-binding properties are affected by multiple local interactions involving various glycosylated EGF-like repeats (Xu et al. 2005). The situation in vertebrates is more complicated, which might not be surprising given the diversity of molecules involved. Besides having several Notch and ligand molecules, vertebrates have also three Fringe homologues: Radical, Manic and Lunatic Fringe. Each of the Fringe proteins might modify Notch interactions in a specific way and the effect of their activity on the different receptor interactions still needs to be explored. The activity of each Fringe molecule could have different properties to the ones studied in Drosophila. For example, unlike the Drosophila Fringe, the chick Lunatic Fringe seems to have an inhibitory effect on Delta-mediated Notch activation (Dale et al. 2003).

Wing margin and dorsal-ventral compartment establishment in Drosophila wing development clearly show that interactions between Notch and its ligands are carefully modulated and titrated (de Celis et al. 1996, Micchelli et al. 1997, Klein \& Arias 1998, Milan \& Cohen 2003). For this reason, it is not surprising that they are tempered by chemical modifications (Panin et al. 1997).

\section{Inhibitory effects of ligands}

In addition to activating the Notch signalling pathway, it has been reported that Notch ligands can also exert an inhibitory effect which is concentration dependent. High levels of ligand induce a ligand inhibitory effect, while lower levels allow the ligand to activate Notch signalling activity (Klein et al. 1997, Micchelli et al. 1997). It has been reported that during Drosophila wing formation this mechanism contributes to restrict Notch signalling activity to the dorsal/ventral (D/V) boundary, regulating correct wing margin formation (de Celis
\& Bray 1997, Klein et al. 1997, Micchelli et al. 1997, Jacobsen et al. 1998, Klein \& Arias 1998). In higher eukaryotes, the role of the ligand inhibitory effect remains largely unexplored but there have been several reports describing this behaviour, for instance in COS-7L and HEK293 cells and during chick development (Henrique et al. 1997, Sakamoto et al. 2002). One of the most suggestive reports in vertebrates is perhaps the studies in Xenopus concerning Delta-like 3 (Dll3), which seems to exhibit only a Notch signalling inhibitory activity (Ladi et al. 2005). Lowell et al. (2000) have even proposed a functional role for ligand inhibition in humans. They suggest that during human keratinocyte differentiation high levels of Delta expression could be acting as an inhibitory mechanism of Notch signalling to maintain the population of stem cells.

The mechanism of ligand inhibitory activity remains however elusive, and even the location where the inhibitory interaction takes place is uncertain (Sakamoto et al. 2002, Glittenberg et al. 2006). The basis of the mechanism is also unclear, and could be explained both by an intercellular ligand-ligand interaction that titrates ligand from an activating Notch interaction or by an intracellular ligand-Notch interaction that prevents signal transduction. There is evidence supporting both models, for instance, there have been reports of intercellular D1-Dl interactions (trans interaction) supporting the first inhibition model (Fehon et al. 1990, Parks et al. 2006). Intracellular N-Dl complexes (cis interaction) have been isolated supporting the $\mathrm{N}-\mathrm{Dl}$ intracellular inhibitory interaction model (Sakamoto et al. 2002).

\section{Regulation of Notch signalling activity}

The interactions of Notch with its ligands in trans result in the activation of the intracellular domain as a transcription factor. The signalling activity is under two levels of regulation. One level involves the transcription factor activity of Notch intracellular domain (NICD) whose activity is tightly downregulated in the nucleus (Kovall 2007). The second level of regulation involves how the transcription factor activity is generated and how this is chosen. The second level of regulation has, in the last years, resulted in uncovering connections between trafficking and the Notch signalling pathway (Le Borgne 2006).

\section{Notch transcriptional regulation}

Notch signalling does not use second messengers and the levels of signalling activity are solely dependent on the nuclear concentration of NICD. Interestingly, endogenous NICD seems to act at very low concentration (below immunodetection levels; Schroeter et al. 1998) and the only way to observe it is with a special antibody raised against the epitope generated by the S3/S4 cleavage (Schroeter et al. 1998). What confers specificity to the expression of Notch target genes is a DNA-binding transcription factor known as CSL (for CBF1 (C-promoter binding factor1), RBP-jk/ 
$\mathrm{Su}(\mathrm{H}) / \mathrm{Lag}-1$ in mammals/Drosophila/C. elegans), which binds to the DNA target gene regions and in the absence of NICD, recruits co-repressors like silencing mediator of retinoid and thyroid receptors (SMRT)/nuclear receptor co-repressor (N-coR), CBF1-interacting co-repressor, hairless and split ends (SPEN) also called SHARP (SMRT/ HDAC-1-associated protein; Kao et al. 1998, Hsieh et al. 1999, Barolo et al. 2002, Oswald et al. 2002; see Fig. 3). The co-repressors associate with histone deacetylase complexes keeping the chromatin in a transcriptional silent mode. When Notch signalling is activated, NICD displaces the co-repressors and associates with CSL in what becomes a ternary complex involving Mastermind. The ternary complex recruits transcription factors such as p300/CBP associated factor/general control of aminoacids synthesis protein 5 (PCAF/GCN5) and CREB-binding protein $(\mathrm{CBP}) / \mathrm{p} 300$-activating responsive genes (Kurooka \& Honjo 2000, Wallberg et al. 2002). This strategy whereby a repressor form of the effectors of a signalling pathway is transformed into an active moiety is characteristic of signal-regulated promoters and presents a number of advantages, most importantly that the effector identifies the targets in the absence of signal (Barolo et al. 2002). Notch-mediated transcriptional activation is downregulated by the degradation of NICD. The mechanism that stops the signalling event involves Mastermind and a protein named Ski-interacting protein (SKIP), which curiously can associate both with the CSL co-repressors and with the CSL-NICD-Mastermind ternary complex (Zhou et al. 2000, Kovall 2007). SKIP and Mastermind are able to recruit kinases that specifically phosphorylate NICD in the TAD and PEST domains. Fbw7/Sel10 ubiquitination of the phosphorylated sites leads to NICD degradation and stops the signalling process in the absence of new NICD entering the nucleus (Fryer et al. 2004). The degradation of NICD is a very effective process as observations over the years demonstrate that the amount of active NICD relative to total Notch must be very small as it is difficult to see (Schroeter et al. 1998, Conboy et al. 2005).

Protein degradation is a very effective method of signalling regulation and one that is clearly used to keep the levels of NICD just above functional threshold. One corollary of this is that for continuous signalling, a continuous Delta input is needed. However, there are other ways of regulating the appearance of NICD, and in the last few years, endocytic traffic has emerged as a central process in the regulation of the levels and activity of Notch.

\section{Notch trafficking}

The concept of endocytic traffic-modulating signalling activity is a recent development in our picture of signal transduction (Gonzalez-Gaitan 2003a,b). It is often thought that signalling events have specific proteins associated with them and thus the notion of signal transduction pathways as a constellation of proteins dedicated to a signalling event. Recent genetic studies in Drosophila have revealed that an increasing number of proteins involved in intracellular traffic are required for the activity of Notch (reviewed in (Le Borgne et al. 2005a)). For example, mutants producing defects on endocytosis, recycling, vesicular sorting and multivesicular body formation present defects on Notch signalling (Poodry 1990, Ramain et al. 2001, Thompson et al. 2005, Vaccari \& Bilder 2005, Jaekel \& Klein 2006). These observations suggest that the activity of signalling pathways is often regulated by

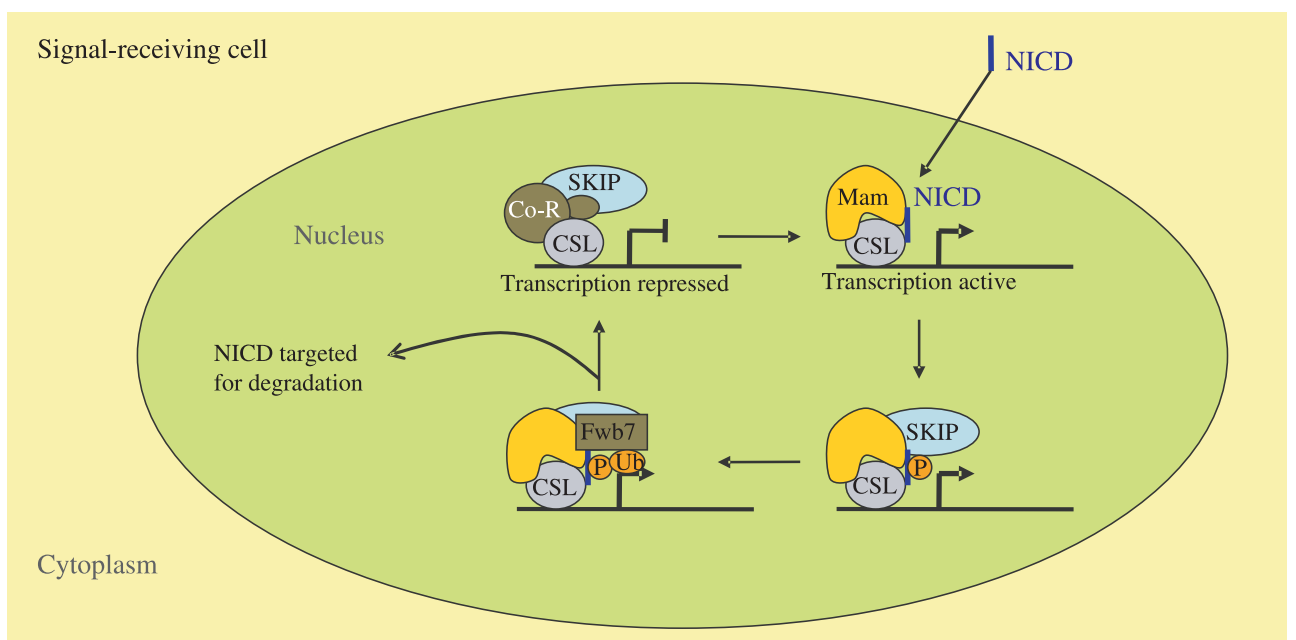

Figure 3 Notch transcriptional regulation. Notch signalling activity is tightly regulated through an efficient process of NICD protein degradation elicited at the nucleus. The CSL-Mam-NICD ternary complex associates with a protein named SKIP which together with Mam recruits kinases that phosphorylate NICD. NICD thus becomes susceptible to ubiquitination by Fbw $7 /$ Sel 10 and this ultimately leads to the protein degradation. This regulatory mechanism keeps a low concentration of NICD present in the nucleus making it necessary that there is continuous signalling for the nuclear influx of NICD to allow for Notch activated transcription to take place. 
cellular processes and this link allows the signalling pathways to be embedded in the global functioning of the cell. One of the first examples of this was the observation that Drosophila temperature-sensitive mutants for shibire, the Drosophila homologue for dynamin, exhibit a Notch-like mutant phenotype during neurogenesis (Poodry 1990, van der Bliek \& Meyerowitz 1991, Chen et al. 1991). Shibire is a GTPase responsible for the endocytic vesicle pinching off from the plasma membrane and this suggested that endocytosis and trafficking might be important for Notch signalling activity. Shibire was later shown to be needed both in the signal-sending and signal-receiving cells for Notch signalling to occur (Seugnet et al. 1997). A typical process of regulation of receptor internalization is protein monoubiquitination which recruits adaptor proteins that elicit endocytosis. Results have suggested that Notch monoubiquitination followed by endocytosis is required for $\gamma$-secretase-mediated cleavage, supporting a role for trafficking in Notch signalling (Gupta-Rossi et al. 2004). Confirmation of the role that endocytosis plays in the regulation of Notch activity has come from studies in Drosophila and although much of this work needs to be confirmed with vertebrate Notch proteins, the universality of mechanisms suggests that this will be the case. Analysis of the sequence of the intracellular domain of Notch reveals the existence of some ubiquitination target regions. Drosophila Notch has in its intracellular region a HECT (homologous to E6-AP carboxyl terminus) domain targeted by members of the HECT-type E3 ubiquitin ligases: Nedd4 and suppressor of Deltex/Itch $(\mathrm{Su}(\mathrm{Dx}) / \mathrm{Itch}$ for Drosophila/ mammalian). Another region of Notch vulnerable to ubiquitination is the ankyrin repeats, which are modified by Deltex (Dx), a ring finger-type ubiquitin ligase (Diederich

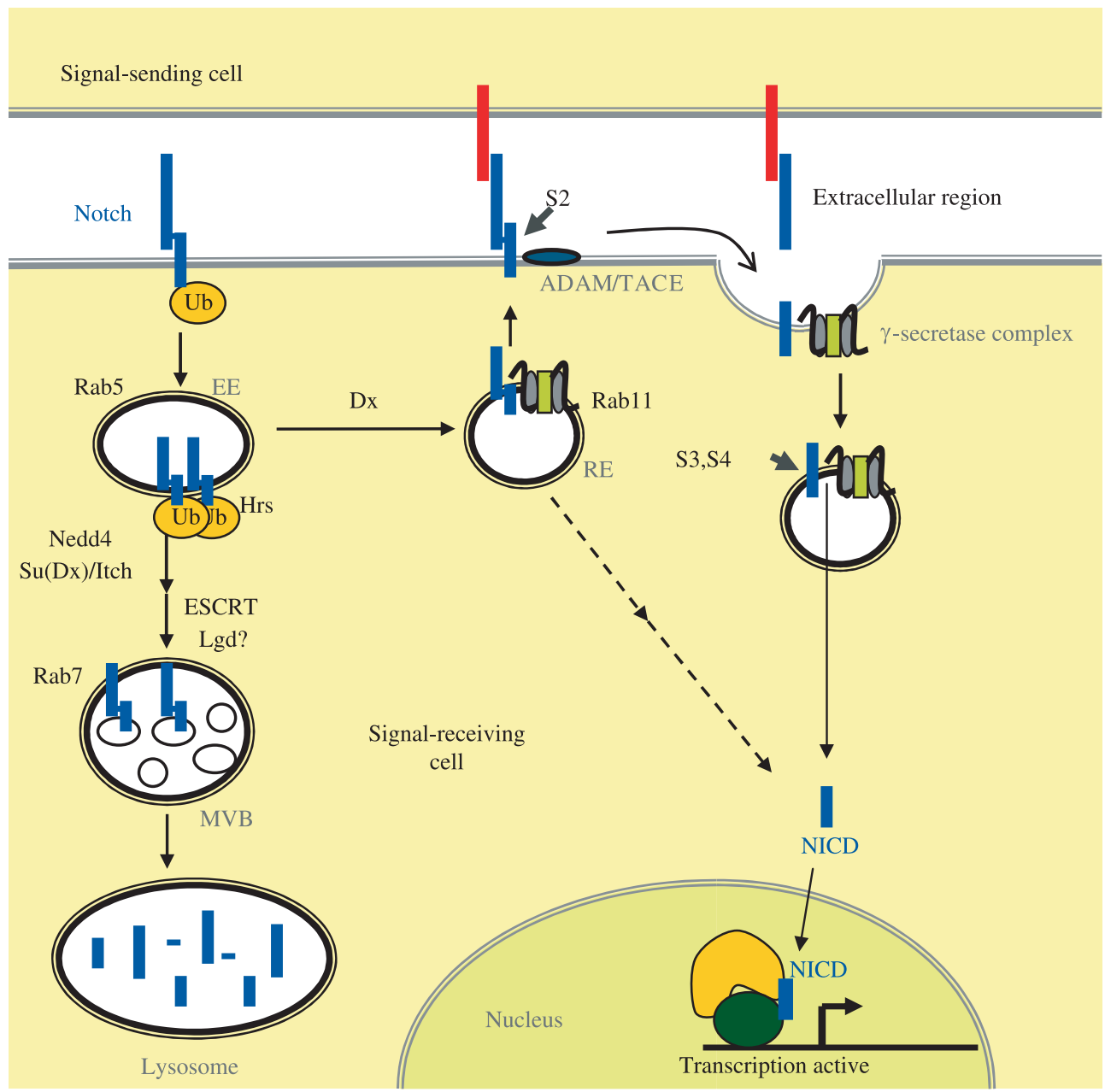

Figure 4 Notch trafficking. Notch is targeted by several ubiquitin ligases. Nedd4 and $\mathrm{Su}(\mathrm{Dx}) / \mathrm{ltch}$ ubiquitination promotes Notch degradation. Ubiquitination by Dx seems to activate Notch signalling in a manner independent of CSL. Ectodomain shedding is required for Notch to signal but ligand-independent Notch signalling has been reported. It is unclear where the presenilin-mediated cleavage takes place but endocytosis has been shown to be crucial for Notch signalling activity. EE, early endosome; MVB, multivesicular body; RE, recycling endosome. 
et al. 1994). Dx is a positive regulator of Notch signalling activity however, both $\mathrm{Su}(\mathrm{Dx})$ and Nedd4 antagonize $\mathrm{Dx}$ (Matsuno et al. 1995, Cornell et al. 1999, Sakata et al. 2004). $\mathrm{Nedd} 4$ and $\mathrm{Su}(\mathrm{Dx})$ seem to act as a regulatory mechanism that inhibits inappropriate ligand-independent activation of Notch signalling (Sakata et al. 2004; see Fig. 4). Su(Dx) is involved in Notch endosomal sorting and appears to target Notch to follow a lysosomal degradation pathway, since it directs Notch to Rab7-positive compartments (Wilkin et al. 2004). Nedd4 also targets Notch for lysosomal degradation (Sakata et al. 2004, Wilkin et al. 2004). It has been suggested that Dx promotes endocytosis of Notch and sorts it towards Rab11-positive compartments (Hori et al. 2004). The creation of a Drosophila deltex null mutant has shown that its activity is tissue specific and that although being a positive regulator of Notch signalling, Dx activity is not essential in any developmental context for Notch signalling to take place (Matsuno et al. 1995, Fuwa et al. 2006). The role and importance of Dx are thus unclear. As Dx has been shown to be involved in ligand-independent late endosomal Notch signalling activation (Hori et al. 2004), it might be involved in general redundant regulatory mechanisms other than the processes of the canonical Notch signalling pathway. This raises questions about the role and nature of the regulatory trafficking processes that may act on Notch signalling.

The observations that different defects in vesicular trafficking affect Notch signalling, confirm on one hand that endocytosis of Notch is required for NICD-mediated signalling and, probably release. On the other hand, they raise the possibility that there exists ligand-independent Notch signalling as some of the activation resulting from alterations in the trafficking machinery, does not require ligands. Thus, it would appear that Notch traffick is an important mechanism to keep Notch from being 'accidentally' activated. It is clear that very little NICD is needed to elicit signalling and it appears that unless Notch is continually turned over, this small amount of NICD can be generated in a ligand-independent manner, i.e. the continuous ubiquitination and degradation of Notch mediated by $\mathrm{Nedd} 4$ and $\mathrm{Su}(\mathrm{Dx})$ are also a form of regulating the steady-state levels of Notch presented at the cell surface. During this default regulatory pathway, Nedd4 and Su(Dx) prevent inappropriate Notch signalling activation (Sakata et al. 2004). The notion that there are ligand-dependent and ligandindependent modes of Notch regulation has been dramatically demonstrated by Jaekel and Klein in their analysis of Lgd, a traffick-associated protein which modulates ligand-independent Notch signalling totally separate from ligand dependent (Jaekel \& Klein 2006). In their work, it was seen that, in Drosophila, Lgd loss of function results in ectopic activation of Notch signalling in a ligand-independent manner. Overexpression of $\mathrm{Lgd}$ enhanced the formation of endocytic vesicles and lead to Notch accumulation in late endosomes. Overexpression of Notch in a mutant Lgd background lead to Notch accumulation in vesicle compartments co-stained for late endosomal markers suggesting that Notch is retained in late endosomes but does not reach the lysosomal compartment. Strikingly, overexpression of Rab5-GFP and Rab7-GFP (GTPases involved in early and late endosomes respectively), rescues the Lgd mutant phenotype suggesting that Lgd might affect the kinetics of vesicular trafficking and this causes ectopic Notch signalling activation (Jaekel \& Klein 2006). A requirement for better understanding the role of general trafficking in keeping signalling events inactive in the absence of a signalling event is essential.

Subcellular localization of S3/S4 cleavage Besides the involvement of trafficking on keeping Notch signalling inactive in the absence of ligand, there are hints that endocytosis and traffic are important in NICD release and signalling. This finds support from the analysis of various mutants in elements of the endocytic pathway. Altering the normal trafficking machinery to study its role in Notch signalling can lead to observations of ligand-dependent and also ligand-independent signalling activation, if one interferes with the maintenance processes of Notch inactivation. One has thus to be very careful when analysing the meaning of these results.

Notch endocytosis mediated by Shibire has been shown to be important for Notch signalling activity (Seugnet et al. 1997). After endocytosis, Notch is localized to early endosomes co-localizing with Rab5. It is in the early endosomes where Notch has to be sorted out towards either protein recycling or the degradation pathway (see Fig. 4). Interestingly, mutants in Rab5 do not impair Notch signalling while mutations in elements of the endosomal sorting complex required for transport (ESCRT) complex do (Lu \& Bilder 2005, Vaccari \& Bilder 2005). The ESCRT complexes are involved in multivesicular body formation and the protein degradation trafficking pathway. Alterations in endosomal protein sorting (e.g. Hrs via ubiquitin binding) and multivesicular bodies formation (via ESCRT complexes activity), affect the regulation of Notch signalling activity. For instance, vps 25 mutants (a member of the ESCRT-II complex) exhibit endosomal accumulation of Notch and ectopic Notch signalling activation (Vaccari \& Bilder 2005). However, the loss of function of sorting components like Hrs, do not activate Notch signalling and can even rescue phenotypes of ligand-independent activation (Jaekel \& Klein 2006). It would thus seem that non-specific Notch signalling activation can take place when accumulation of Notch occurs in a specific non-determined trafficking compartment. These results are demonstrative of the importance of trafficking regulation for proper monitorization of Notch signalling activity. Most important, kinetics of endosomal trafficking is likely to be a relevant factor. The fact that NICD ligand-independent activity caused by blockage in the late endosomal compartments (Jaekel \& Klein 2006) can be relieved by activation of the traffic through the early endosomal compartments indicates that Notch signalling is mediated by an 'optimal trafficking' activity.

One of the important issues raised by these observations about trafficking and Notch signalling concerns the possible location of the S3 cleavage event. It has been argued that the 
presenilin complex could act at the cell surface (Kaether et al. 2006) and this has always been somewhat at odds with observation that Psn resides somewhere in the endocytic pathway (Ray et al. 1999, Pasternak et al. 2003). The recent observations emphasize that accumulation of Notch in the endocytic pathway, probably in a post Rab5 and/orRab7 compartment, can lead to its activation via S3 cleavage. This would suggest that this cleavage does occur in the some endosomal compartment.

Another important question opened by these studies is the relationship between the ligand-dependent and ligandindependent activation. Whether ligand-dependent and ligand-independent S3 cleavage occurs in the same compartment, or in different ones, how the process of ectodomain shedding for ligand-independent Notch signalling occurs, are all still open questions. A deeper understanding of these cellular mechanisms will most likely be instrumental in the full comprehension of the Notch signalling regulation.

\section{Ligand trafficking}

The phenotype of the shibire mutants in Drosophila cannot distinguish between autonomous and non-autonomous requirements of the relevant gene products, i.e. it is possible that endocytosis is required both in the signalling and signalreceiving cell. A number of observations suggest that endocytosis of the Notch ligands is also required for the signalling event (Le Borgne 2006, Nichols et al. 2007). Genes identified in genetic screens for neurogenic mutants show impaired ligand endocytosis (Parks et al. 2000). Furthermore analysis of zebrafish mutants uncovered Mind bomb as an ubiquitin ligase required for Delta endocytosis and this was followed by the observation of similar proteins in Drosophila (Neuralized and D-Mind bomb 1 and 2). These proteins act on Delta to promote ubiquitination and endocytosis and thus enhance the signalling ability of the signal-sending cells (Pavlopoulos et al. 2001, Le Borgne \& Schweisguth 2003, Itoh et al. 2003, Lai et al. 2005, Bardin \& Schweisguth 2006). Ubiquitination of the DSL ligands makes them targets of adaptor proteins such as liquid facets (Lqf, a homologue for epsin) which promotes endocytosis (Wang \& Struhl 2004, 2005).

At this moment, the exact role of ligand endocytosis is unclear. Two main models have been put forward. One possibility is that ligand endocytosis plays an important role in the shedding of the Notch ectodomain by exerting a pulling force. This would then facilitate Notch cleavage by exposing the substrate for ADAM/TACE/Kuzbanian proteases. There is some recent experimental evidence in favour of this model (Nichols et al. 2007). Another possibility is that ligand endocytosis is required for ligand post-translational modifications which render the ligand competent for activating Notch signalling activity when recycled back to the plasma membrane (Wang \& Struhl 2004, Le Borgne et al. 2005a, Wilkin \& Baron 2005). The latter model is supported by the fact that Delta lacking its intracellular domain is not able to elicit Notch signalling activity (Sun \& Artavanis-Tsakonas 1996, Nichols et al. 2007).

Many questions remain unanswered when ligand regulation is concerned and models about other functions of the ligands have been put forward. There have been reports of ligand cleavage by ADAM metalloproteases and $\gamma$-secretase activity. This has given rise to some speculation over whether ligands can modulate Notch signalling by the release of soluble forms of ligand or whether the ligands could somehow perform a signalling event of their own (Qi et al. 1999, LaVoie \& Selkoe 2003, Six et al. 2003).

Notch signalling is based on a very simple mechanism, the release of a membrane-tethered transcription factor but its regulation contrasts, as described, by being quite complex. On the next section, we shall focus on exploring the multiple functions of Notch by looking at paradigms of its activity in development and adult organisms.

\section{Functions of Notch}

Notch signalling is used iteratively in many developmental events. There are two modalities which can be construed as three. The first one is the one that has led to much of our understanding and function of Notch: a permissive function in which it contributes to a decision between two alternative fates. This can happen within a large population, 'lateral inhibition' or between two sister cells, 'asymmetric cell fate assignation'. However, Notch signalling can also be used in a more instructive manner, as in the case of boundary formation in Drosophila and, perhaps, during somitogenesis in vertebrates.

\section{Lateral inhibition}

The best characterized function of Notch is probably 'lateral inhibition', a process of central importance in the assignation of cell fates and their spatial patterning (Heitzler \& Simpson 1993, Le Borgne \& Schweisguth 2003, Gibert \& Simpson 2003). The notion of lateral inhibition is derived from the observation that during development, groups of cells emerge that are assigned a common developmental potential but only some cells within the group adopt that potential. Those that adopt the fate suppress the same fate in the others: lateral inhibition. This mechanism has been well characterized during the selection for a sensory organ precursor (SOP) in insect neurogenesis (Fig. 5A). During development, groups of ectodermal cells with a neural potential emerge known as proneural clusters. Notch signalling activity inhibits the prospective neural fate. By the amplification of small differences within the proneural cluster cells, one of them will acquire higher level of Delta and inhibit the neural potential of the neighbouring cells using Notch signalling activity. Lateral inhibition establishes in this way the pattern of bristles of Drosophila (Heitzler \& Simpson 1993, Martin-Bermudo et al. 1995, Parks et al. 1997, Ruth et al. 1983). In a mammalian system, for example, studies in mice 
(A)

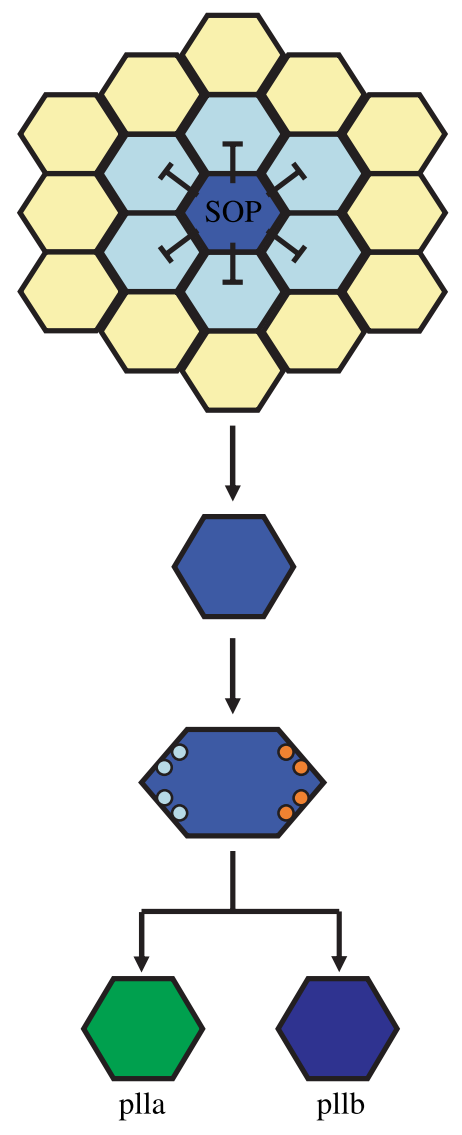

(B)



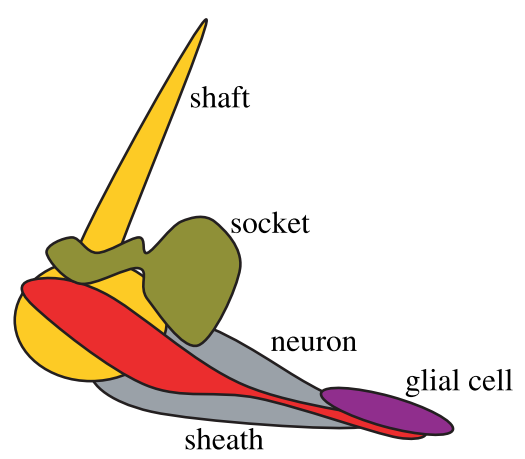

Figure 5 Drosophila neurogenesis. (A) Lateral inhibition in neurogenesis ensures that within a proneural cluster (cells in blue) a single cell will become an SOP and inhibit its neighbours from acquiring a neuronal fate. (B) A sensory organ is formed by four cells: a socket cell, a bristle cell, a sheath cell and a neuron. Within a proneural cluster, once an SOP is chosen by lateral inhibition it will mature and divide by asymmetric cell division into a plla and a pllb cell. Several steps of asymmetric cell division will give rise to all sensory organ cells and cell fate is ensured by Notch lateral inhibition.

show that lateral inhibition plays also an important role in hair cell development in the inner ear (Kiernan et al. 2005).

Delta endocytosis is important for the ligand to be able to elicit Notch signalling. Drosophila Delta has in its intracellular region monoubiquitination motifs which can be targeted by Neuralized and Mind bomb1 (Le Borgne et al. 2005b). The bearded gene family $(b r d)$ antagonizes Neuralized activity (Bardin \& Schweisguth 2006). It has been suggested that these proteins might play a role in SOP selection, since they are absent from SOP cells and expressed in non-SOP cells in proneural clusters. Notch signalling has a positive regulation of brd expression (Bardin \& Schweisguth 2006). Inhibition of Delta signalling ability in Notch active non-SOP cells could amplify the small differences in the proneural cluster and help in the establishment of bristle pattern formation (Castro et al. 2005, Bardin \& Schweisguth 2006).

\section{Asymmetric cell fate assignation}

Notch is mainly involved in binary cell fate decision which will ultimately lead to pattern formation in the organism. Lateral inhibition is one process of binary cell fate choice; another one is associated with asymmetric cell division and relies on cell polarization. Epithelial cells of the Drosophila wing imaginal disc are polarized cells containing adherens and septate junctions in the apical region. Notch and Delta are located in the apical region of the cells restricting the signalling activation to this region. The role and mediators of Notch and Delta apical localization remain elusive (Sasaki et al. 2007). However, Par-1 (a polarity protein) has been suggested to be a mediator of Delta localization and Par-1 loss of function (induced through RNAi) has a neurogenic phenotype (Bayraktar et al. 2006). In cells that divide symmetrically, cell 
polarity and Notch signalling activity might be simply intimately related with vesicular trafficking and any deregulation of the trafficking machinery will produce defects unto both. There could, however, be a more direct relationship between regulation of signalling activity by a polarized localization of Notch and ligand but this remains unclear (Lu \& Bilder 2005). Asymmetric cell division has a more direct role in cell polarity regulation of Notch signalling. Asymmetric distribution of cell fate determinants prior to mitosis can determine a specific cell fate identity of the daughter cells. The best studied example of this is neurogenesis in Drosophila. Asymmetric distribution of regulators of Notch signalling activity determines the identity of the daughter cells as signalsending or signal-receiving cell. Once Notch signalling is elicited, the cells differentiate according to binary cell fate decision mediated by Notch (Frise et al. 1996, Le Borgne \& Schweisguth 2003, Hutterer \& Knoblich 2005). This asymmetric distribution of Notch regulators in neurogenesis is regulated by polarity proteins such as Bazooka, PAR-6, DaPKC, Inscuteable and Partner of Inscuteable (Schober et al. 1999, Wodarz et al. 1999). The mechanism of bristle formation will now be described in more detail (Fig. 5B). After the SOP cell is chosen, it gives rise to the pI cell. The pI cell goes through a series of four asymmetric cell divisions in which regulators of Notch signalling (e.g. Numb and Neuralized) are distributed asymmetrically between daughter cells, rendering one cell able to elicit Notch signalling activity (pIIb cell) and the other only responsive to Notch signalling (pIIa cell). Numb and Neuralized are localized to the pIIb cell. They are involved in enhancing Delta endocytosis increasing Delta's signalling ability. Numb inhibits Notch signalling ability making the pIIb cell only functional as a signal-sending cell. The signal-sending cell will inhibit the sister cell from acquiring the same cell fate by activating Notch signalling. The process of asymmetric distribution of Notch regulators is repeated in the multiple cell divisions giving rise in the end to a glial cell and the cells that form the bristle: socket cell, bristle cell, sheath cell and neuron (Rhyu et al. 1994, Le Borgne \& Schweisguth 2003, Koelzer \& Klein 2003, Hutterer \& Knoblich 2005; see Fig. 5B). Numb homologues have been identified in vertebrate species suggesting that this might be a general conserved mechanism of cell fate assignation (Knoblich 2001).

Another important example of binary cell fate choices is the role of Notch in the maintenance of stem cell populations. Notch mediates many decisions of whether a cell should differentiate or remain in an undifferentiated state either in embryonic or in post-embryonic stem cell systems (Chiba 2006).

\section{Boundary formation}

Notch is involved in boundary establishment in different events during development. An example in vertebrates is the formation of boundaries between the prospective somites during somitogenesis or in invertebrates the establishment of the $\mathrm{D} / \mathrm{V}$ boundary in the wing imaginal disc (de Celis et al. 1997, Micchelli et al. 1997, Barrantes et al. 1999). These processes can be quite complex and involve multiple Notch regulatory mechanisms.

Looking at the vertebrate example, in somite formation, we find a very elegant system of a transcriptional oscillator. The continuous cycle of activation and inactivation of Notch transcriptional activity leads to the pattern of somite formation and segmental boundary in the presomitic mesoderm. The full mechanism of activation and inactivation of transcriptional activity is unclear but seems to involve negative feedback loops mediated by Notch target genes. The models may, however, become more complicated as there is increasing evidence for the involvement of the Wnt pathway (Palmeirim et al. 1997, Pasini et al. 2001, Aulehla et al. 2003, Giudicelli \& Lewis 2004).

Looking at the Drosophila wing imaginal disc example, Notch signalling activity is restricted to the $\mathrm{D} / \mathrm{V}$ boundary where it establishes the necessary cues for keeping both fields separated and regulating the growth and patterning of the dorsal and ventral compartments. Notch activity is constrained to the $\mathrm{D} / \mathrm{V}$ boundary by restrictive gene expression. During early third larval instar, Serrate and Fringe are only expressed in the dorsal compartment, Delta only on the ventral compartment and Notch on both compartments. Fringe inhibits Serrate from inducing Notch signalling dorsally. The absence of Fringe ventrally does not allow for Notch signalling to occur. At the boundary, Serrate can interact with unglycosylated Notch from the ventral side and Delta with Fringe glycosylated Notch from the dorsal side. This restricts Notch signalling activity to the $\mathrm{D} / \mathrm{V}$ boundary, a pattern made more robust by a feedback loop mechanism. Notch signalling activity drives expression of $\mathrm{Wg}$ which will elicit expression of Ser and $\mathrm{Dl}$ outside the $\mathrm{D} / \mathrm{V}$ boundary. Ser and $\mathrm{Dl}$ expression then further activate Notch signalling at the boundary. Notch signalling also drives the expression of Cut which has been proposed to have an inhibitory effect on ligand expression at the $\mathrm{D} / \mathrm{V}$ boundary. Outside the $\mathrm{D} / \mathrm{V}$ boundary, high levels of ligand inhibit Notch signalling activity (de Celis \& Bray 1997, Micchelli et al. 1997). Another model put forward to explain the role of Notch in $\mathrm{D} / \mathrm{V}$ boundary formation/maintenance suggests the existence of a non-transcriptional Notch function involving regulation of the actin cytoskeleton (Major \& Irvine 2005).

There are numerous examples of the role of Notch in boundary formation like the segmentation of zebrafish hindbrain, but the type of mechanisms involved follow somehow the same principles present in the examples previously described (Pasini et al. 2001).

\section{The role of Notch in the development of endocrine glands}

The development of some of the classical endocrine systems follows similar principles to those of other organs and therefore it is not surprising to find that generic analysis reveals a role for Notch signalling at different stages of this process. For example, during pituitary gland development Notch target genes Hes 1 and Hes 5 have been shown to control the progenitor cell pool as 
observed by the severe hypoplasia exhibited in mice lacking Hes 1 and Hes 5 (Kita et al. 2007). Moreover, Notch signalling can also influence cell fate decision besides precursor cell number and consequently organ size (Raetzman et al. 2007). A similar effect can be seen in pancreas development where Hes1 null mice pancreas precursor cells also undergo premature differentiation leading to the formation of a hypoplastic pancreas (Jensen et al. 2000). Neurogenin3, a bHLH gene, has a proendocrine role in pancreas development and its activity is antagonized by the Hes genes (Pang et al. 1994). Notch is thus essential for the cell fate decision between progenitor/exocrine and endocrine pancreatic cells (Pang et al. 1994). The largest endocrine organ, the gut, uses Notch signalling initially to regulate stem cell differentiation towards a secretory or absorptive cell fate, through lateral inhibition. Stem cells with higher $\mathrm{N}$ and lower Dl expression will differentiate into epithelial absorptive cells and stem cells with lower $\mathrm{N}$ and with higher Dl expression will adopt a secretory cell fate. The epithelial secretory cells undergo further differentiation into specific cell lineages and this is regulated by $b H L H$ genes which can be modulated by Hes1. Hes1 antagonizes the bHLH transcription factors regulating the endocrine progenitor cells pool (reviewed in Lee \& Kaestner 2004).

Thus, although there is nothing special about Notch signalling and the endocrine signalling it is clear that understanding the involvement and the control of Notch signalling in the development of these organs allows novel views and interesting insights into this process. This knowledge is made more pressing because of the involvement of mutations in Notch in a number of diseases, some of them associated with endocrine organs (Leimeister et al. 2000, Lowell et al. 2000).

\section{CSL-independent Notch signalling}

There is increasing evidence that Notch can have effects on cellular processes that are independent of its $\mathrm{CBF} / \mathrm{Su}(\mathrm{H})$ activity. For example, in vertebrates, Notch has been shown to inhibit muscle cell differentiation in a CSL-independent manner (Shawber et al. 1996). Studies of the differentiation of mouse myoblasts (primary myogenic C2C12 cells) into myotubes have shown that expression of truncated forms of Notch lacking the ability to interact with CBF1-dependent promoter still inhibit myoblast differentiation (Shawber et al. 1996, Nofziger et al. 1999).

However, most of the evidence for a CBF-independent activity of Notch is derived from Drosophila, in particular from the study of two kinds of alleles of Notch: the Abruptex, $(A x)$ and the Microchaetae defective $(M c d)$ classes. The $A x$ class represents a collection of point mutants centred around the EGF-like repeats 24-29 region while the $M c d$ class is a series of deletions of protein domains C-terminal to the ANK repeats. Both classes of mutants exhibit gain of function phenotypes during neurogenesis that are independent of $\mathrm{Su}(\mathrm{H})$ but dependent on shaggy, which encodes the Drosophila homologue of GSK3 $\beta$ and plays a central role in Wnt signalling (Brennan et al. 1997, 1999b). These observations raised the suggestion that there is a functional connection between Notch and Wnt signalling and this has been supported by further studies in Drosophila (Axelrod et al. 1996, Brennan et al. 1999b, Lawrence et al. 2000, Hayward et al. 2005).

The activity of Wnt signalling is mediated by $\beta$-catenin and the existing evidence suggests that Notch modulates Wnt signalling by setting up a threshold for the function of $\beta$-catenin (Hayward et al. 2005). While much of this evidence is derived from Drosophila, there is also evidence from vertebrates that Notch signalling can act on $\beta$-catenin. For example, in mice, Notch 1 has been shown to act as a tumour suppressor by repressing $\beta$-catenin-mediated signalling revealing the importance of understanding this relationship (Nicolas et al. 2003). Additionally, in the development of osteoblasts, Notch has been shown to suppress this fate in favour of chondroblasts by suppression of $\beta$-catenin activity (Deregowski et al. 2006).

Table 2 Diseases caused by Notch signalling defects

\section{Symptoms}

Disease

Alagille syndrome

CADASIL syndrome

T-cell acute lymphoblastic leukaemia

Spondylocostal dysostosis (SD) death
Kidney, eye, heart and skeleton developmental problems and also defects in bile duct formation leading to liver problems

Autosomal vascular disorder linked with a variety of Mutations on Notch 1 and 3 symptoms ranging from migraines to premature

Aggressive tumour derived from T-cell progenitors due to increased Notch signalling activation

Rib defects causing abnormalities in vertebral segmentation and trunk size
Cause

Mutations on the Jagged1 gene

Mutations involving either the Notch heterodimerization domain or the PEST domain. Translocation of a truncated form of Notch resulting in signalling hyperactivation

Mutations in Delta-like 3. Epigenetic results suggest Lunatic Fringe mutations could also cause SD 
It has been suggested that this activity serves to set up a threshold for Wnt signalling (Hayward et al. 2005) and it will be interesting to get more insights into the mechanisms which lead to crosstalk between these pathways.

\section{Notch and disease}

Given the importance of Notch signalling in development, it is no surprise, that there are several human diseases linked to defects in genes involved in Notch signalling (see Table 2). Mutations on the Jagged 1 gene are responsible for Alagille syndrome which is normally diagnosed in the first 2 years of life. This is an autosomal dominant mutation that causes defects in bile duct formation leading to liver problems, and is also responsible for kidney, eye, heart and skeleton developmental problems (Artavanis-Tsakonas 1997, Li et al. 1997, Oda et al. 1997) The great variety of expression of the disease suggests that other factors may influence the outcome such as genetic properties of regulators of Notch signalling activity (Harper et al. 2003). Mutations on the human Notch 1 and 3 are responsible for the cerebral autosomal dominant arteriopathy with subcortical infarcts and leukoencephalopathy syndrome. Mutations on Notch 1 and 3 lead to an autosomal vascular disorder resulting in the loss of the arteriolar vascular smooth muscle cells which are substituted by granular eosinophilic material. One specific feature is its late onset usually around the age of 45 years. This disease is linked with a variety of symptoms ranging from migraines and subcortical ischemic strokes to progressive dementia and premature death (Gridley 2003, Harper et al. 2003). Another very serious condition caused by deregulation of Notch signalling activity is T-cell acute lymphoblastic leukaemia. The major cause for this condition arises from mutations involving either the Notch heterodimerization domain or the PEST domain (involved in Notch degradation; Weng et al. 2004). This condition can also arise from a translocation of a truncated form of Notch which becomes juxtaposed with the promoter/enhancer of T-cell receptor $\beta$. This event is caused by mistakes during TCR recombination and leads to ligandindependent Notch signalling activity with oncogenic consequences (Gridley 2003, Sjolund et al. 2005). There is also a family of diseases resulting in vertebral defects called spondylocostal dysostosis. Essentially, it is caused by mutations in Dll3 resulting in rib defects that lead to abnormalities in vertebral segmentation and trunk size (Gridley 2003). Understanding the mechanisms of Notch signalling regulation is of course crucial in the development of therapeutic approaches for the treatment of these diseases.

\section{Future perspectives}

Many Notch regulatory processes have been identified but are not yet truly characterized. Notch activity regulation by ligand inhibitory effect is well described but its mechanism of action is still unclear. The role and mechanisms of Notch and ligand trafficking are not well understood, and CSL-independent Notch signalling remains undefined, both as a molecular pathway and in its effects. Further work is necessary to understand Notch signalling in all its complexity. This should provide insights into how to tackle Notch signalling in a more specific way in order to better approach different clinical contexts.

\section{Acknowledgements}

We would like to thank P Hayward, M Ehebauer and D Gupta for comments and discussion on the manuscript. The Welcome Trust supports the work of A M A and U-M F is recipient of a $\mathrm{PhD}$ fellowship from Fundação para a Ciéncia e Tecnologia.

The authors declare that there is no conflict of interest that would prejudice the impartiality of this scientific work.

\section{References}

Artavanis-Tsakonas S 1997 Alagille syndrome-a notch up for the Notch receptor. Nature Genetics 16 212-213.

Aulehla A, Wehrle C, Brand-Saberi B, Kemler R, Gossler A, Kanzler B \& Herrmann BG 2003 Wnt3a plays a major role in the segmentation clock controlling somitogenesis. Developmental Cell 4 395-406.

Axelrod JD, Matsuno K, Artavanis-Tsakonas S \& Perrimon N 1996 Interaction between Wingless and Notch signaling pathways mediated by dishevelled. Science 271 1826-1832.

Bardin AJ \& Schweisguth F 2006 Bearded family members inhibit neuralizedmediated endocytosis and signaling activity of Delta in Drosophila. Developmental Cell 10 245-255.

Barolo S, Stone T, Bang AG \& Posakony JW 2002 Default repression and Notch signaling: hairless acts as an adaptor to recruit the corepressors Groucho and dCtBP to suppressor of hairless. Genes and Development 16 1964-1976.

Barrantes IB, Elia AJ, Wunsch K, Hrabe de Angelis MH, Mak TW, Rossant J, Conlon RA, Gossler A \& de la Pompa JL 1999 Interaction between Notch signalling and Lunatic fringe during somite boundary formation in the mouse. Current Biology 9 470-480.

Bayraktar J, Zygmunt D \& Carthew RW 2006 Par-1 kinase establishes cell polarity and functions in Notch signaling in the Drosophila embryo. Journal of Cell Science 119 711-721.

van der Bliek AM \& Meyerowitz EM 1991 Dynamin-like protein encoded by the Drosophila shibire gene associated with vesicular traffic. Nature 351 411-414.

Le Borgne R 2006 Regulation of Notch signalling by endocytosis and endosomal sorting. Current Opinion in Cell Biology 18 213-222.

Le Borgne R \& Schweisguth F 2003 Unequal segregation of neuralized biases Notch activation during asymmetric cell division. Developmental Cell $\mathbf{5}$ 139-148.

Le Borgne R, Bardin A \& Schweisguth F 2005a The roles of receptor and ligand endocytosis in regulating Notch signaling. Development 132 1751-1762.

Le Borgne R, Remaud S, Hamel S \& Schweisguth F $2005 b$ Two distinct E3 ubiquitin ligases have complementary functions in the regulation of delta and serrate signaling in Drosophila. PLoS Biology 3 e96.

Bray S 1998 Notch signalling in Drosophila: three ways to use a pathway. Seminars in Cell and Developmental Biology 9 591-597.

Brennan K, Tateson R, Lewis K \& Arias AM 1997 A functional analysis of Notch mutations in Drosophila. Genetics 147 177-188.

Brennan K, Klein T, Wilder E \& Arias AM 1999a Wingless modulates the effects of dominant negative notch molecules in the developing wing of Drosophila. Developmental Biology 216 210-229. 
Brennan K, Tateson R, Lieber T, Couso JP, Zecchini V \& Arias AM $1999 b$ The abruptex mutations of notch disrupt the establishment of proneural clusters in Drosophila. Developmental Biology 216 230-242.

Bruckner K, Perez L, Clausen H \& Cohen S 2000 Glycosyltransferase activity of Fringe modulates Notch-Delta interactions. Nature 406 411-415.

Castro B, Barolo S, Bailey AM \& Posakony JW 2005 Lateral inhibition in proneural clusters: cis-regulatory logic and default repression by suppressor of hairless. Development 132 3333-3344.

de Celis JF \& Bray S 1997 Feed-back mechanisms affecting Notch activation at the dorsoventral boundary in the Drosophila wing. Development 124 3241-3251.

de Celis JF, Garcia-Bellido A \& Bray SJ 1996 Activation and function of Notch at the dorsal-ventral boundary of the wing imaginal disc. Development 122 359-369.

de Celis JF, Bray S \& Garcia-Bellido A 1997 Notch signalling regulates veinlet expression and establishes boundaries between veins and interveins in the Drosophila wing. Development 124 1919-1928.

Chen MS, Obar RA, Schroeder CC, Austin TW, Poodry CA, Wadsworth SC \& Vallee RB 1991 Multiple forms of dynamin are encoded by shibire, a Drosophila gene involved in endocytosis. Nature 351 583-586.

Chiba S 2006 Notch signaling in stem cell systems. Stem Cells 24 2437-2447.

Conboy IM, Conboy MJ, Wagers AJ, Girma ER, Weissman IL \& Rando TA 2005 Rejuvenation of aged progenitor cells by exposure to a young systemic environment. Nature $\mathbf{4 3 3}$ 760-764.

Cornell M, Evans DA, Mann R, Fostier M, Flasza M, Monthatong M, Artavanis-Tsakonas S \& Baron M 1999 The Drosophila melanogaster suppressor of deltex gene, a regulator of the Notch receptor signaling pathway, is an E3 class ubiquitin ligase. Genetics 152 567-576.

Dale JK, Maroto M, Dequeant ML, Malapert P, McGrew M \& Pourquie O 2003 Periodic notch inhibition by lunatic fringe underlies the chick segmentation clock. Nature 421 275-278.

Deregowski V, Gazzerro E, Priest L, Rydziel S \& Canalis E 2006 Notch 1 overexpression inhibits osteoblastogenesis by suppressing $\mathrm{Wnt} / \beta$-catenin but not bone morphogenetic protein signaling. Journal of Biological Chemistry $2816203-6210$.

Diederich RJ, Matsuno K, Hing H \& Artavanis-Tsakonas S 1994 Cytosolic interaction between deltex and Notch ankyrin repeats implicates deltex in the Notch signaling pathway. Development 120 473-481.

Fehon RG, Kooh PJ, Rebay I, Regan CL, Xu T, Muskavitch MA \& Artavanis-Tsakonas S 1990 Molecular interactions between the protein products of the neurogenic loci Notch and Delta, two EGF-homologous genes in Drosophila. Cell 61 523-534.

Fleming RJ 1998 Structural conservation of Notch receptors and ligands. Seminars in Cell and Developmental Biology 9 599-607.

Fortini ME \& Artavanis-Tsakonas S 1994 The suppressor of hairless protein participates in notch receptor signaling. Cell 79 273-282.

Frise E, Knoblich JA, Younger-Shepherd S, Jan LY \& Jan YN 1996 The Drosophila numb protein inhibits signaling of the Notch receptor during cell-cell interaction in sensory organ lineage. PNAS 93 11925-11932.

Fryer CJ, White JB \& Jones KA 2004 Mastermind recruits CycC:CDK8 to phosphorylate the Notch ICD and coordinate activation with turnover. Molecular Cell 16 509-520.

Fuwa TJ, Hori K, Sasamura T, Higgs J, Baron M \& Matsuno K 2006 The first deltex null mutant indicates tissue-specific deltex-dependent Notch signaling in Drosophila. Molecular Genetics and Genomics 275 251-263.

Gibert JM \& Simpson P 2003 Evolution of cis-regulation of the proneural genes. International Journal of Developmental Biology 47 643-651.

Giudicelli F \& Lewis J 2004 The vertebrate segmentation clock. Current Opinion in Genetics and Development 14 407-414.

Glittenberg M, Pitsouli C, Garvey C, Delidakis C \& Bray S 2006 Role of conserved intracellular motifs in Serrate signalling, cis-inhibition and endocytosis. EMBO Journal 25 4697-4706.

Gonzalez-Gaitan M 2003a Signal dispersal and transduction through the endocytic pathway. Nature Review. Molecular and Cellular Biology 4 213-224.

Gonzalez-Gaitan M $2003 b$ Endocytic trafficking during Drosophila development. Mechanisms of Development 120 1265-1282.
Gordon WR, Vardar-Ulu D, Histen G, Sanchez-Irizarry C, Aster JC \& Blacklow SC 2007 Structural basis for autoinhibition of Notch. Nature Structural and Molecular Biology 14 295-300.

Greenwald I 1985 Lin-12, a nematode homeotic gene, is homologous to a set of mammalian proteins that includes epidermal growth factor. Cell $\mathbf{4 3}$ $583-590$.

Greenwald I 1994 Structure/function studies of lin-12/Notch proteins. Current Opinion in Genetics and Development 4 556-562.

Gridley T 2003 Notch signaling and inherited disease syndromes. Human Molecular Genetics 12 R9-R13.

Gupta-Rossi N, Six E, LeBail O, Logeat F, Chastagner P, Olry A, Israel A \& Brou C 2004 Monoubiquitination and endocytosis direct $\gamma$-secretase cleavage of activated Notch receptor. Journal of Cell Biology 166 73-83.

Haines N \& Irvine KD 2003 Glycosylation regulates Notch signalling. Nature Review. Molecular and Cellular Biology 4 786-797.

Hambleton S, Valeyev NV, Muranyi A, Knott V, Werner JM, McMichael AJ, Handford PA \& Downing AK 2004 Structural and functional properties of the human notch-1 ligand binding region. Structure 12 2173-2183.

Harper JA, Yuan JS, Tan JB, Visan I \& Guidos CJ 2003 Notch signaling in development and disease. Clinical Genetics 64 461-472.

Hayward P, Brennan K, Sanders P, Balayo T, DasGupta R, Perrimon N \& Martinez Arias A 2005 Notch modulates Wnt signalling by associating with Armadillo/ $\beta$-catenin and regulating its transcriptional activity. Development 132 1819-1830.

Heitzler P \& Simpson P 1993 Altered epidermal growth factor-like sequences provide evidence for a role of Notch as a receptor in cell fate decisions. Development 117 1113-1123.

Henrique D, Hirsinger E, Adam J, Le Roux I, Pourquie O, Ish-Horowicz D \& Lewis J 1997 Maintenance of neuroepithelial progenitor cells by DeltaNotch signalling in the embryonic chick retina. Current Biology 7 661-670.

Hori K, Fostier M, Ito M, Fuwa TJ, Go MJ, Okano H, Baron M \& Matsuno K 2004 Drosophila deltex mediates suppressor of hairless-independent and lateendosomal activation of Notch signaling. Development 131 5527-5537.

Hsieh JJ, Zhou S, Chen L, Young DB \& Hayward SD 1999 CIR, a corepressor linking the DNA binding factor CBF1 to the histone deacetylase complex. PNAS 96 23-28.

Hu QD, Ma QH, Gennarini G \& Xiao ZC 2006 Cross-talk between F3/contactin and Notch at axoglial interface: a role in oligodendrocyte development. Developmental Neuroscience 28 25-33.

Hutterer A \& Knoblich JA $2005 \mathrm{Numb}$ and $\alpha$-Adaptin regulate Sanpodo endocytosis to specify cell fate in Drosophila external sensory organs. EMBO Reports 6 836-842.

Itoh M, Kim CH, Palardy G, Oda T, Jiang YJ, Maust D, Yeo SY, Lorick K, Wright GJ, Ariza-McNaughton L et al. 2003 Mind bomb is a ubiquitin ligase that is essential for efficient activation of Notch signaling by Delta. Developmental Cell 4 67-82.

Jacobsen TL, Brennan K, Arias AM \& Muskavitch MA 1998 Cis-interactions between Delta and Notch modulate neurogenic signalling in Drosophila. Development 125 4531-4540.

Jaekel R \& Klein T 2006 The Drosophila Notch inhibitor and tumor suppressor gene lethal (2) giant discs encodes a conserved regulator of endosomal trafficking. Developmental Cell 11 655-669.

Jensen J, Pedersen EE, Galante P, Hald J, Heller RS, Ishibashi M, Kageyama R, Guillemot F, Serup P \& Madsen OD 2000 Control of endodermal endocrine development by Hes-1. Nature Genetics 24 36-44.

Kaether C, Haass C \& Steiner H 2006 Assembly, trafficking and function of $\gamma$-secretase. Neuro-Degenerative Diseases 3 275-283.

Kao HY, Ordentlich P, Koyano-Nakagawa N, Tang Z, Downes M, Kintner CR, Evans RM \& Kadesch T 1998 A histone deacetylase corepressor complex regulates the Notch signal transduction pathway. Genes and Development 12 2269-2277.

Kidd S \& Lieber T 2002 Furin cleavage is not a requirement for Drosophila Notch function. Mechanisms of Development 115 41-51.

Kiernan AE, Cordes R, Kopan R, Gossler A \& Gridley T 2005 The Notch ligands DLL1 and JAG2 act synergistically to regulate hair cell development in the mammalian inner ear. Development 132 4353-4362. 
Kita A, Imayoshi I, Hojo M, Kitagawa M, Kokubu H, Ohsawa R, Ohtsuka T, Kageyama R \& Hashimoto N 2007 Hes1 and hes 5 control the progenitor pool, intermediate lobe specification, and posterior lobe formation in the pituitary development. Molecular Endocrinology 21 1458-1466.

Klein T \& Arias AM 1998 Interactions among Delta, Serrate and Fringe modulate Notch activity during Drosophila wing development. Development 125 2951-2962.

Klein T, Brennan K \& Arias AM 1997 An intrinsic dominant negative activity of serrate that is modulated during wing development in Drosophila. Developmental Biology 189 123-134.

Knoblich JA 2001 Asymmetric cell division during animal development. Nature Review. Molecular and Cellular Biology 2 11-20.

Koelzer S \& Klein T 2003 A Notch-independent function of suppressor of hairless during the development of the bristle sensory organ precursor cell of Drosophila. Development 130 1973-1988.

Kopan R, Schroeter EH, Weintraub H \& Nye JS 1996 Signal transduction by activated mNotch: importance of proteolytic processing and its regulation by the extracellular domain. PNAS 93 1683-1688.

Kovall RA 2007 Structures of CSL, Notch and Mastermind proteins: piecing together an active transcription complex. Current Opinion in Structural Biology 17 117-127.

Kurooka H \& Honjo T 2000 Functional interaction between the mouse notch1 intracellular region and histone acetyltransferases PCAF and GCN5. Journal of Biological Chemistry 275 17211-17220.

Ladi E, Nichols JT, Ge W, Miyamoto A, Yao C, Yang LT, Boulter J, Sun YE, Kintner C \& Weinmaster G 2005 The divergent DSL ligand Dll3 does not activate Notch signaling but cell autonomously attenuates signaling induced by other DSL ligands. Journal of Cell Biology 170 983-992.

Lai EC, Roegiers F, Qin X, Jan YN \& Rubin GM 2005 The ubiquitin ligase Drosophila mind bomb promotes Notch signaling by regulating the localization and activity of Serrate and Delta. Development 132 2319-2332.

LaVoie MJ \& Selkoe DJ 2003 The Notch ligands, Jagged and Delta, are sequentially processed by $\alpha$-secretase and presenilin $/ \gamma$-secretase and release signaling fragments. Journal of Biological Chemistry 278 34427-34437.

Lawrence N, Klein T, Brennan K \& Martinez Arias A 2000 Structural requirements for notch signalling with delta and serrate during the development and patterning of the wing disc of Drosophila. Development 127 3185-3195.

Lee CS \& Kaestner KH 2004 Clinical endocrinology and metabolism. Development of gut endocrine cells. Best Practice and Research. Clinical Endocrinology and Metabolism 18 453-462.

Lei L, Xu A, Panin VM \& Irvine KD 2003 An O-fucose site in the ligand binding domain inhibits Notch activation. Development 130 6411-6421.

Leimeister C, Schumacher N, Steidl C \& Gessler M 2000 Analysis of HeyL expression in wild-type and Notch pathway mutant mouse embryos. Mechanisms of Development 98 175-178.

Li L, Krantz ID, Deng Y, Genin A, Banta AB, Collins CC, Qi M, Trask BJ, Kuo WL, Cochran J et al. 1997 Alagille syndrome is caused by mutations in human Jagged1, which encodes a ligand for Notch1. Nature Genetics 16 243-251.

Lissemore JL \& Starmer WT 1999 Phylogenetic analysis of vertebrate and invertebrate Delta/Serrate/LAG-2 (DSL) proteins. Molecular Phylogenetics and Evolution 11 308-319.

Logeat F, Bessia C, Brou C, LeBail O, Jarriault S, Seidah NG \& Israel A 1998 The Notch1 receptor is cleaved constitutively by a furin-like convertase. PNAS 95 8108-8112.

Lowell S, Jones P, Le Roux I, Dunne J \& Watt FM 2000 Stimulation of human epidermal differentiation by delta-notch signalling at the boundaries of stem-cell clusters. Current Biology 10 491-500.

Lu H \& Bilder D 2005 Endocytic control of epithelial polarity and proliferation in Drosophila. Nature Cell Biology 7 1232-1239.

Lubman OY, Korolev SV \& Kopan R 2004 Anchoring notch genetics and biochemistry; structural analysis of the ankyrin domain sheds light on existing data. Molecular Cell 13 619-626.

Maine EM, Lissemore JL \& Starmer WT 1995 A phylogenetic analysis of vertebrate and invertebrate Notch-related genes. Molecular Phylogenetics and Evolution 4 139-149.
Major RJ \& Irvine KD 2005 Influence of Notch on dorsoventral compartmentalization and actin organization in the Drosophila wing. Development 132 3823-3833.

Martin-Bermudo MD, Carmena A \& Jimenez F 1995 Neurogenic genes control gene expression at the transcriptional level in early neurogenesis and in mesectoderm specification. Development 121 219-224.

Matsuno K, Diederich RJ, Go MJ, Blaumueller CM \& Artavanis-Tsakonas S 1995 Deltex acts as a positive regulator of Notch signaling through interactions with the Notch ankyrin repeats. Development 121 2633-2644.

Metz C \& Bridges CB 1917 Incompatibility of the mutant race in. Drosophila. PNAS 3 673-678.

Micchelli CA, Rulifson EJ \& Blair SS 1997 The function and regulation of cut expression on the wing margin of Drosophila: Notch, wingless and a dominant negative role for Delta and Serrate. Development 124 1485-1495.

Milan M \& Cohen SM 2003 A re-evaluation of the contributions of Apterous and Notch to the dorsoventral lineage restriction boundary in the Drosophila wing. Development 130 553-562.

Mumm JS, Schroeter EH, Saxena MT, Griesemer A, Tian X, Pan DJ, Ray WJ \& Kopan R 2000 A ligand-induced extracellular cleavage regulates $\gamma$-secretase-like proteolytic activation of Notch1. Molecular Cell 5 197-206.

Nichols JT, Miyamoto A, Olsen SL, D'Souza B, Yao C \& Weinmaster G 2007 DSL ligand endocytosis physically dissociates Notch1 heterodimers before activating proteolysis can occur. Journal of Cell Biology 176 445-458.

Nicolas M, Wolfer A, Raj K, Kummer JA, Mill P, van Noort M, Hui CC, Clevers H, Dotto GP \& Radtke F 2003 Notch1 functions as a tumor suppressor in mouse skin. Nature Genetics 33 416-421.

Nofziger D, Miyamoto A, Lyons KM \& Weinmaster G 1999 Notch signaling imposes two distinct blocks in the differentiation of $\mathrm{C} 2 \mathrm{C} 12$ myoblasts. Development 126 1689-1702.

Oda T, Elkahloun AG, Pike BL, Okajima K, Krantz ID, Genin A, Piccoli DA, Meltzer PS, Spinner NB, Collins FS et al. 1997 Mutations in the human Jagged 1 gene are responsible for Alagille syndrome. Nature Genetics 16 235-242.

Okajima T \& Irvine KD 2002 Regulation of notch signaling by O-linked fucose. Cell 111 893-904.

Okajima T, Xu A, Lei L \& Irvine KD 2005 Chaperone activity of protein O-fucosyltransferase 1 promotes notch receptor folding. Science $\mathbf{3 0 7}$ 1599-1603.

Oswald F, Kostezka U, Astrahantseff K, Bourteele S, Dillinger K, Zechner U, Ludwig L, Wilda M, Hameister H, Knochel W et al. 2002 SHARP is a novel component of the Notch/RBP-JK signalling pathway. EMBO Journal 21 5417-5426.

Palmeirim I, Henrique D, Ish-Horowicz D \& Pourquie O 1997 Avian hairy gene expression identifies a molecular clock linked to vertebrate segmentation and somitogenesis. Cell 91 639-648.

Pang K, Mukonoweshuro C \& Wong GG 1994 Beta cells arise from glucose transporter type 2 (Glut2)-expressing epithelial cells of the developing rat pancreas. PNAS 91 9559-9563.

Panin VM, Papayannopoulos V, Wilson R \& Irvine KD 1997 Fringe modulates Notch-ligand interactions. Nature 387 908-912.

Parks AL, Huppert SS \& Muskavitch MA 1997 The dynamics of neurogenic signalling underlying bristle development in Drosophila melanogaster. Mechanisms of Development 63 61-74.

Parks AL, Klueg KM, Stout JR \& Muskavitch MA 2000 Ligand endocytosis drives receptor dissociation and activation in the Notch pathway. Development 127 1373-1385.

Parks AL, Stout JR, Shepard SB, Klueg KM, Dos Santos AA, Parody TR, Vaskova M \& Muskavitch MA 2006 Structure-function analysis of Delta trafficking, receptor binding, and signaling in Drosophila. Genetics .

Parks AL, Stout JR, Shepard SB, Klueg KM, Dos Santos AA, Parody TR, Vaskova M \& Muskavitch MA 2006 Structure-function analysis of Delta trafficking, receptor binding and signaling in Drosophila. Genetics 174 19471961.

Pasini A, Henrique D \& Wilkinson DG 2001 The zebrafish hairy/ enhancer-of-split-related gene her6 is segmentally expressed during the early development of hindbrain and somites. Mechanisms of Development 100 317-321. 
Pasternak SH, Bagshaw RD, Guiral M, Zhang S, Ackerley CA, Pak BJ, Callahan JW \& Mahuran DJ 2003 Presenilin-1, nicastrin, amyloid precursor protein, and $\gamma$-secretase activity are co-localized in the lysosomal membrane. Journal of Biological Chemistry 278 26687-26694.

Pavlopoulos E, Pitsouli C, Klueg KM, Muskavitch MA, Moschonas NK \& Delidakis C 2001 Neuralized encodes a peripheral membrane protein involved in delta signaling and endocytosis. Developmental Cell 1 807-816.

Poodry CA 1990 Shibire, a neurogenic mutant of Drosophila. Developmental Biology 138 464-472.

Poulson D 1939 Effects of Notch deficiencies. Drosophila Information Services 12 64-65.

Qi H, Rand MD, Wu X, Sestan N, Wang W, Rakic P, Xu T \& ArtavanisTsakonas S 1999 Processing of the notch ligand delta by the metalloprotease Kuzbanian. Science 283 91-94.

Raetzman LT, Cai JX \& Camper SA 2007 Hes1 is required for pituitary growth and melanotrope specification. Developmental Biology 304 455-466.

Ramain P, Khechumian K, Seugnet L, Arbogast N, Ackermann C \& Heitzler P 2001 Novel Notch alleles reveal a Deltex-dependent pathway repressing neural fate. Current Biology 11 1729-1738.

Rand MD, Grimm LM, Artavanis-Tsakonas S, Patriub V, Blacklow SC, Sklar J \& Aster JC 2000 Calcium depletion dissociates and activates heterodimeric notch receptors. Molecular and Cellular Biology 20 1825-1835.

Ray WJ, Yao M, Mumm J, Schroeter EH, Saftig P, Wolfe M, Selkoe DJ, Kopan R \& Goate AM 1999 Cell surface presenilin-1 participates in the $\gamma$-secretase-like proteolysis of Notch. Journal of Biological Chemistry 274 36801-36807.

Rebay I, Fleming RJ, Fehon RG, Cherbas L, Cherbas P \& ArtavanisTsakonas S 1991 Specific EGF repeats of Notch mediate interactions with Delta and Serrate: implications for Notch as a multifunctional receptor. Cell 67 687-699.

Rhyu MS, Jan LY \& Jan YN 1994 Asymmetric distribution of numb protein during division of the sensory organ precursor cell confers distinct fates to daughter cells. Cell 76 477-491.

Ruth L, Fernando J, Ursula D \& José AC-O 1983 On the phenotype and development of mutants of early neurogenesis in Drosophila melanogaster. Development Genes and Evolution 192 62-74.

Sakamoto K, Ohara O, Takagi M, Takeda S \& Katsube K 2002 Intracellular cell-autonomous association of Notch and its ligands: a novel mechanism of Notch signal modification. Developmental Biology 241 313-326.

Sakata T, Sakaguchi H, Tsuda L, Higashitani A, Aigaki T, Matsuno K \& Hayashi S 2004 Drosophila Nedd4 regulates endocytosis of notch and suppresses its ligand-independent activation. Current Biology 14 2228-2236.

Sanchez-Irizarry C, Carpenter AC, Weng AP, Pear WS, Aster JC \& Blacklow SC 2004 Notch subunit heterodimerization and prevention of ligandindependent proteolytic activation depend, respectively, on a novel domain and the LNR repeats. Molecular and Cellular Biology 24 9265-9273.

Sasaki N, Sasamura T, Ishikawa HO, Kanai M, Ueda R, Saigo K \& Matsuno K 2007 Polarized exocytosis and transcytosis of Notch during its apical localization in Drosophila epithelial cells. Genes Cells 12 89-103.

Schober M, Schaefer M \& Knoblich JA 1999 Bazooka recruits inscuteable to orient asymmetric cell divisions in Drosophila neuroblasts. Nature $\mathbf{4 0 2}$ 548-551.

Schroeter EH, Kisslinger JA \& Kopan R 1998 Notch-1 signalling requires ligand-induced proteolytic release of intracellular domain. Nature 393 382-386.

Seugnet L, Simpson P \& Haenlin M 1997 Requirement for dynamin during Notch signaling in Drosophila neurogenesis. Developmental Biology 192 585-598.

Shawber C, Nofziger D, Hsieh JJ, Lindsell C, Bogler O, Hayward D \& Weinmaster G 1996 Notch signaling inhibits muscle cell differentiation through a CBF1-independent pathway. Development 122 3765-3773.
Six E, Ndiaye D, Laabi Y, Brou C, Gupta-Rossi N, Israel A \& Logeat F 2003 The Notch ligand Delta1 is sequentially cleaved by an ADAM protease and $\gamma$-secretase. PNAS 100 7638-7643.

Sjolund J, Manetopoulos C, Stockhausen MT \& Axelson H 2005 The Notch pathway in cancer: differentiation gone awry. European Journal of Cancer $\mathbf{4 1}$ 2620-2629.

Struhl G \& Adachi A 1998 Nuclear access and action of notch in vivo. Cell 93 649-660.

Sun X \& Artavanis-Tsakonas S 1996 The intracellular deletions of Delta and Serrate define dominant negative forms of the Drosophila Notch ligands. Development 122 2465-2474.

Thompson BJ, Mathieu J, Sung HH, Loeser E, Rorth P \& Cohen SM 2005 Tumor suppressor properties of the ESCRT-II complex component Vps25 in Drosophila. Developmental Cell 9 711-720.

Vaccari T \& Bilder D 2005 The Drosophila tumor suppressor vps25 prevents nonautonomous overproliferation by regulating notch trafficking. Developmental Cell 9 687-698.

Wallberg AE, Pedersen K, Lendahl U \& Roeder RG 2002 p300 and PCAF act cooperatively to mediate transcriptional activation from chromatin templates by notch intracellular domains in vitro. Molecular and Cellular Biology 22 7812-7819.

Wang W \& Struhl G 2004 Drosophila epsin mediates a select endocytic pathway that DSL ligands must enter to activate Notch. Development 131 5367-5380.

Wang W \& Struhl G 2005 Distinct roles for Mind bomb, neuralized and Epsin in mediating DSL endocytosis and signaling in Drosophila. Development 132 2883-2894.

Weng AP, Ferrando AA, Lee W, Morris JPt, Silverman LB, Sanchez-Irizarry C, Blacklow SC, Look AT \& Aster JC 2004 Activating mutations of NOTCH1 in human T cell acute lymphoblastic leukemia. Science 306 269-271.

Wharton KA, Johansen KM, Xu T \& Artavanis-Tsakonas S 1985 Nucleotide sequence from the neurogenic locus notch implies a gene product that shares homology with proteins containing EGF-like repeats. Cell $\mathbf{4 3}$ 567-581.

Wilkin MB \& Baron M 2005 Endocytic regulation of Notch activation and down-regulation (review). Molecular Membrane Biology 22 279-289.

Wilkin MB, Carbery AM, Fostier M, Aslam H, Mazaleyrat SL, Higgs J, Myat A, Evans DA, Cornell M \& Baron M 2004 Regulation of notch endosomal sorting and signaling by Drosophila Nedd4 family proteins. Current Biology 14 2237-2244.

Wodarz A, Ramrath A, Kuchinke U \& Knust E 1999 Bazooka provides an apical cue for inscuteable localization in Drosophila neuroblasts. Nature $\mathbf{4 0 2}$ 544-547.

Wolfe MS 2006 The $\gamma$-secretase complex: membrane-embedded proteolytic ensemble. Biochemistry 45 7931-7939.

Xu A, Lei L \& Irvine KD 2005 Regions of Drosophila Notch that contribute to ligand binding and the modulatory influence of Fringe. Journal of Biological Chemistry 280 30158-30165.

Yochem J, Weston K \& Greenwald I 1988 The Caenorhabditis elegans lin-12 gene encodes a transmembrane protein with overall similarity to Drosophila Notch. Nature 335 547-550.

Zhou S, Fujimuro M, Hsieh JJ, Chen L, Miyamoto A, Weinmaster G \& Hayward SD 2000 SKIP, a CBF1-associated protein, interacts with the ankyrin repeat domain of NotchIC to facilitate NotchIC function. Molecular and Cellular Biology 20 2400-2410.

\section{Received in final form 8 June 2007 \\ Accepted 11 June 2007 \\ Made available online as an Accepted Preprint 11 June 2007}

